\title{
Tecnologías del cuerpo: Una clave de lectura en dos textos de Francisco Rivas
}

\author{
Technologies of the body: Reading key in two Francisco \\ Rivas's texts
}

$\frac{\text { Pía GutiérRez Díaz }}{\text { plgutier@uc.cl }}$

" O estaba en el salitre con los héroes oscuros", así es el primer verso 1 del epígrafe escogido por Francisco Rivas para su novela Martes tristes publicada por primera vez el año 1983. Versos que corresponden al poema "Los Hombres del Nitrato" de Pablo Neruda y que anticipan el color tierra de quienes juegan, la mayor parte del tiempo, la historia que nos contará aquí este autor chileno -médico de profesión y escritor en un hábito de vida-. La novela es la genealogía de un pueblo: Ricaventura. En él se desarrolla el cruce de sus habitantes para la formación estratégica de familias y sociedades, éste es el relato de un pueblo viviente que muta ante los ojos del lector gracias a inversionistas que depositan su vida y construyen el mito de un grupo de casas en medio de la pampa. Asistimos a la Historia de un trasplante y de hombres implantados que desarrollan una organización del habitar en torno a la actividad salitrera o, en contraparte, a su rechazo, al relato de los hombres y mujeres imaginados, al contener de sus cuerpos construidos por la palabra del narrador que identifica los sentidos de quien lee con las marcas de una cultura. Leer atentamente permite, entonces, desarrollar una clave de lectura, una pauta de entrada a la escritura de Rivas desde esa corporalidad que reproduce las marcas que se siguen inscribiendo hoy en los cuerpos de los integrantes de la sociedad chilena. De este modo, y aunque la ficción de la novela nos hable del ayer por medio de un relato mágico, el cuerpo se concibe en una clave cotidiana que muchas veces invierte o pone en crisis el orden imperante del relato y, por extensión, de su contexto de lectura. 
La narración acoge así la corporalidad de sus personajes, sus características físicas, particularidades de un andar, modos de comer y deformidades; los hábitos y restricciones impuestos por la higiene, la religión, la empresa o por los decretos sanitarios; la diferenciación de sexos y de etnias con sus respectivos imaginarios; la manipulación del deseo y de la reproducción. El cuerpo se construye, en consecuencia, delimitando los espacios habitados y siendo la cicatriz de las diversas esferas sociales, de cierta ideología y de la administración del poder en Martes tristes.

De igual manera, en otros relatos breves del autor la construcción de los cuerpos se convierte en un eje que posibilita el desarrollo de la acción y que determina la lectura. Así ocurre en "El hombre de la gárgola", relato perteneciente al libro de cuentos titulado El Banquete publicado en editorial Pehuén en el año 1992, las normativas en el cuerpo de los personajes permiten al igual que en Martes tristes inscribir el relato en una tradición literaria y hacer conexiones contextuales que develan una poética autorial. Intentaré entonces, a lo largo de estas páginas delinear algunas características de dicha configuración de los cuerpos en los textos antes mencionados y vislumbrar entradas que reflexionen entorno a la narrativa de Francisco Rivas.

\section{CUERPO COMO REFUERZO DE IMAGINARIOS}

Si bien el propio Francisco Rivas no se inscribe en una generación literaria determinada, su diálogo con la tradición narrativa se puede hacer desde la evidencia del cuerpo como un objeto que determina la aprehensión de los personajes al interior del relato: Por ejemplo, en Martes tristes y en "El hombre de la gárgola" la monstruosidad será un signo que guíen la lectura. Diamela Eltit en su artículo "Clases de cuerpo y cuerpos de clase" publicado en la revista Aisthesis, indica:

El cuerpo como diseño social, como mapa discursivo elocuente para establecer construcciones de sentido, continua imperturbable su recorrido en tanto agudo campo de prueba de los sistemas sociales [...] De la misma manera que la historia recoge el trazado del cuerpo de los acontecimientos, la literatura acopia en sus ficciones las intensidades que portan los relatos corporales y los dispone en una exacta correlación con los sistemas productivos y sus técnicas (2005: 9).

El diálogo que establece Eltit entre los cuerpos de Alsino de Pedro Prado, 
Patas de perro de Carlos Droguett y el Obsceno pájaro de la noche de José Donoso, determina una tradición en la narrativa chilena que utiliza la deformidad y la monstruosidad para hablarnos de los conflictos entre centro y periferia, el cuerpo masculino deformado, con alas, mitad hombre mitad perro, o mudo o feminizado, es la evidencia de un conflicto discursivo que necesita el soporte de un cuerpo que ponga en evidencia el desajuste con el discurso homogeneizador. Cercano a este mecanismo se rastrea también en los relatos de Rivas el cuerpo deforme; en Martes tristes, por ejemplo, Torcidos es un personaje que ha traicionado el honor del Ejército para vender en ese gesto su inserción a la patria, dicho personaje aparece como un tirano a sueldo, torcido en su andar y en su actuar:

Y vio otra vez como el embajador del gobierno francés iba llenando de divisas la mano extendida del coronel Torcidos, aquella con la que lo sobornaba para transportar a París las dos mejores salas del museo de Lima, esa noche del ochenta y uno, cuando abrió la puerta del despacho del oficial, lo que le costó el grado y la obligación de enrolarse en la campaña de la sierra (106).

Torcidos es poseedor de un cuerpo que así como su nombre dejan en evidencia la deformidad de su honor, la codicia inscrita con que atemoriza a sus contrincantes, pero a la vez marca a este hombre que tras la guerra se convertirá en uno de los matones de Bernardo Coca, dispuesto a hacer desaparecer Ricaventura con tal de extraer de ahí las riquezas de la veta más grande de salitre: "Torcidos se deslizó por una escala de servicio con su maleta de cartón. Con su llamativa corpulencia, su mirada de cuervo y su terno brillante trató de pasar inadvertido en un vagón de tercera clase y lo logró” (83).

Torcidos es un hombre capaz de matar, de olvidar jerarquías, su venta de la sala más importante del museo de Lima expone su ignorancia convirtiendo en moneda artículos que poseen un valor cultural para un pueblo determinado, rompe así los códigos de la comunidad desconociendo el valor del arte salvo por su valor en el mercado y se tuerce, se desvía de la norma y vende al extranjero el patrimonio, en ese acto se vende a sí mismo y se configura como portador de su marca de brutalidad, de ese uniforme y esa corpulencia atemorizadora.

El cuerpo con características extrañas, monstruosas, se repetirá a lo largo del relato, el olor corporal, reminiscencia de un mundo animal y primigenio, será la herencia que Ramón Gracia deje a sus hijos. Este personaje, un implantado en Ricaventura y ex soldado errante, decide construir la historia 
del pueblo casi por corazonada y siguiendo su promesa de volver al lugar de las palmeras, de la antigua cruz del Adelantado. Ramón se vuelca así en la tarea de organizar la salvaguarda de este villorrio para construirse a sí mismo, es el hombre que encarnará por momentos la ley y se adueñará del poder dominando a sus vecinos; se nos muestra el origen de una estirpe nacida del deseo de ser comunidad. Testarudo y lleno de coraje, decide armar ese espacio como el escenario de su vida, compra a su mujer siendo aún una niña y prepara un colchón con plumas de un pájaro de mal augurio para concebir a su primer hijo, hace oídos sordos a las advertencias del cura Ventura (párroco olvidado de Ricaventura que será la voz moral que resguarde continuamente el poder depositado en Ramón). Este neofundador decide que su voluntad prime sobre la voluntad del orden natural. Deseo de civilización que choca con las leyes de dios y del mundo andino, enfrentamiento arrogante que se impone ante los designios de una ley a priori que reproduce los sedimentos del "orden" de una sociedad como la chilena. Así, en esta desobediencia y como muestra de que la naturaleza prima sobre el deseo de un hombre, el designio de la fábula castiga a Ramón Gracia, su hijo expele olor animal semejante al de las pieles que quiere comerciar su padre:

En la noche, al mudar al niño, Matilde le notó algo raro, como un olor a carnero que le impregnaba la piel y ahuyentaba los zancudos. Ramón, que estudiaba la forma de llevar el comercio de pieles más al sur, había sentido el olor. 'Cierra las ventanas - gritó- que hasta aquí se huelen los guanacos'. 'No son los guanacos -dijo- es tu hijo' (42).

El niño porta la desobediencia del padre; parece ser que en ese gesto el mundo le recuerda a este fundador que hay un orden que no puede alterarse, el sistema de ley de valores al interior del relato castiga la osadía del padre, y le da prueba de que esa osadía también será la que lo lleve a un caos en el futuro de Ricaventura. El designio no puede ser alterado, este pueblo que nace como obra de un testarudo hombre no puede más que ser devorado por el fuego arrasador que desde el inicio del relato se nos anuncia como la causa del ocaso de Ricaventura, la utopía no puede más que concretarse en un espacio corrompido, monstruosamente distópico. Pero existe un gesto en la escritura de Rivas que invierte, o al menos da una esperanza a este nuevo orden, pues será el hedor del hijo de Ramón el que más adelante salve el simulacro de Ricaventura como Nuevo Jerusalén. En un acto desesperado para escapar de la extracción del salitre y desaparición del pueblo, los habitantes dirigidos por Ramón deciden construir justo al final de la veta un 
nuevo pueblo escenario que disfrazarán del propio. Contra el tiempo logran incluso trasladar cuatro de las cinco palmeras que sirven de seña para que el guía identifique la tierra prometida:

Torcidos hizo un gesto y diez hombres rodearon a Ramón.

- ¡Y ahora me dirás dónde mierda queda Ricaventura! Dijo alzando la voz. -Como no -Ramón escupió- como trece millas hacia allá- y levantó la barbilla señalando el sur.

Torcidos giró en redondo, desconfiado. [...]

-Mucho olor a animal para tan poca gente- Torcidos olfateó el aire.

-Es mi hijo que tiene el pellejo apestado- dijo Ramón retrocediendo.

-¿Tú hijo?, tráelo- ordenó Torcidos.

Ramón caminó hasta su casa y regresó a los pocos minutos con el pequeño Ramón de la mano. El niño trotaba feliz a su lado. Torcidos se inclinó sobre la criatura y arrugó la nariz (108).

El hedor del niño disimula los rastrojos dejados por los animales trasplantados al pueblo escenario y determina el fracaso de la expedición de Torcidos. En este gesto escritural se siembra una esperanza que indica que a pesar del designio, alterar el orden puede tener, quizás en el espacio del simulacro, un éxito liberador.

En el cuento "El hombre de la gárgola", Lionel Cariccio, niño de 11 años, es hijo de Gaspar, plomero que emigra al pueblito de Alucenas desde Buenos Aires en búsqueda de mejores posibilidades de trabajo. Lionel se diferencia del común de los niños porque es sordo y esta condición impide que pueda entrar a una de las tres escuelas del pueblo. En el relato no escuchar es una carencia que sin duda inquieta a los otros habitantes de esta localidad argentina; la marca de una diferencia, la escasez de uno de los sentidos pone en alerta a los otros posicionados como "normales" e incluso a la máxima autoridad del pueblo quien justifica el rechazo. Héctor Filemón, jefe de gendarmería, ante las quejas del padre porque su hijo no es admitido en ningún recinto educacional, responde suelto de cuerpo, arreglándose los pantalones que contienen su cuerpo obeso: "No estoy seguro de si es la directora la que se opone o la junta de padres de la escuela" (3). Más adelante el gendarme advertirá a Gaspar: "Oiga [...] éste es un lugar muy tranquilo". A lo que Gaspar responde: “A este paso va a dejar de serlo!” (37). Esta amenaza ante el orden en apariencia, a una tranquilidad que parece ser símil del estancamiento, se hará efectiva no gracias al actuar de la figura del plomero, sino gracias a un acto de su hijo sordo -personaje que sin duda dialoga 
con el mudito donosiano-. Lionel, en su mundo silencioso se convierte en un excelente aprendiz del oficio de su padre. El final del relato nos lleva, después de entuertos y de problemas entre Gaspar y los representantes del orden, a un ajusticiamiento por manos del propio niño. El buen observador, monstruo apartado, castigará a la autoridad deformando su rostro:

En la sala, en su asiento de sargento estaba muerto Filemón: en su cara roja y escaldada todavía podía verse, como fulgurantes ojos de pescado, algunas gotas de estaño derretido.

Porque eso era lo que Cariccio recién había visto. La mascarilla mortuoria de Filemón y su expresión aterrorizada, vaciada en la profunda inconsciencia que provoca la grapa, que lo miraba desde el techo de la señorita Monsálvez. Su hijo, sin duda, era un buen aprendiz (53).

Existe a lo largo del cuento un espacio en que se expresa el deseo de Cariccio padre por la solterona del pueblo; él descubre este cuerpo femenino mientras trabaja en el ajuste de las tuberías de la casa de la solterona, es ahí cuando ve en esta mujer un cuerpo deseable, rompiendo también el lugar en que la ha encasillado el resto del pueblo, ella ha sido ligada a un cuerpo asexuado:

La señorita Monsálvez, que señora no había sido nunca, era una solterona exigente, pero simpática. Vestida siempre de luto, 'por si alguien la toma por viuda' le oiría después decir a Bartolo, resultó atractiva para Cariccio. Su piel blanca y bien cuidada y todas sus formas aunque menguadas, presentes, lo llevaron a deducir que andaba por los cincuenta (43).

Será luego de alterar el orden de lo deseable que Cariccio descubre la gárgola en mal estado de la fachada de la casa de la señorita Monsálvez, casa emblemática que muestra el apogeo de la familia en su diseño, y en un gesto conmovido por el recuerdo de su hijo, decide repararla. Reparar esa fachada será luego una tarea terminada por Lionel, quien pondrá en lugar de la gárgola la máscara que daría muerte al jefe de los gendarmes.

Existe un traspaso entre el deseo desajustado y un ajuste simbólico que remueve la normalidad y establece una monstruosidad en la periferia argentina. Así como en Martes tristes, la historia de este niño monstruo es también la historia de un pueblo inventado que incorpora en su relato los cuerpos anómalos y la presencia de un Torcidos enemigo así como los hedores y aromas que expelen los hijos de Ramón, la historia de Camello, la blancura de 
la caprichosa hija de Duhamel, La Pulpa administrando el placer desde una silla/trono, todos estos personajes son narrados en un coexistir como una estrategia de avance en el apogeo y caída de Ricaventura. En el cuento "El hombre de la gárgola", el cuerpo cobra importancia como evidencia de la pugna de poder, del establecimiento de un sistema que se sitúa en conflicto con lo fuera de la norma, asimismo Ricaventura escapa en sus inicios de la normatividad imperante y propone un nuevo orden, aquí, por ejemplo, cuerpos mutados y discriminados por origen étnico serán vitales para la consolidación de un nuevo sistema. Los hermanos Paz serán emblema de los problemas provocados por las fronteras promovidas por el hombre blanco:

Néstor Paz y sus hermanos Nicanor y Nonato vivían en Ricaventura desde el final de la guerra. [...] Elijah Bonson, propietario de la multinacional ballenera que operaba en los mares del sur, descubrió que Néstor había nacido en Bolivia, lo acusó ante las autoridades locales de presunto espía (37).

Néstor es castigado y humillado, la imagen del loco, del vagabundo que debe ser señalado para reforzar la normalidad del resto de los habitantes se encarna en él, la furia racista ante el hombre oscuro es reajustada en Ricaventura, el narrar revela que la nacionalidad en el mundo andino no tiene mucho que ver con la pertenencia, "el nacimiento en un país o en el vecino no dependía, a veces, más que de una buena cosecha o de una mala sequía" (38). Los hermanos Paz serán en un momento del relato fundamentales para el establecimiento de un sistema comercial en el pueblo.

El antropólogo Clifford Geertz nos recuerda que el cuerpo no es sólo un asunto biológico, sino el resultado de una cultura, las diferenciaciones que se escriben sobre él o se describen de su hacer tienen entonces que ver con los límites que establece el quehacer de un grupo: "La cultura, más que agregarse, por así decirlo, a un animal terminado o virtualmente terminado, fue un elemento y un elemento fundamental, en la producción de ese animal mismo [...] Entre las estructuras culturales, el cuerpo y el cerebro, se creó un sistema de realimentación positiva en el cual cada parte moldeaba el progreso de la otra” (1989: 48). Parece ser que el cuerpo que acepta y valora el mestizaje, su carácter híbrido, corresponde con la fertilidad y bendición de un grupo; el Embajador, personaje blanco capaz de amar a una mujer mapuche y asumir los riesgos de integrarla a un sistema cercano al poder, es quien fertiliza los valles del centro del país con sus huesos untados en salitre, su consecuencia y conciencia de que el origen étnico no implica poder 
sobre la explotación de un hombre sobre otro incorpora un nuevo espacio de lectura.

Sin duda, Francisco Rivas da cuerpo a sus palabras y construye corporalidades en el espacio de su lenguaje, dichas construcciones generan movimientos en la representación que actúan performáticamente, reconstruyendo desde la reproducción o la alteración de imágenes convencionales sobre la corporalidad un espacio sincrético que permite avanzar en las historias y en el posicionamiento ideológico de su literatura. El cuerpo no sólo como recipiente sino como modelador.

He intentado dar algunas luces sobre dichas materialidades, es claro que sería necesario considerar muchas más esferas, las ligadas a la sexualidad y el género, a las tecnologías de intervención en los cuerpos, profundizar en las descripciones étnicas y sus posicionamientos, pero espero de algún modo proponer una pauta desde donde quizás podría abarcarse más exhaustivamente la poética de este autor chileno.

\section{REFERENCIAS}

Geertz, Clifford. 1989. La interpretación de las culturas. Barcelona: Gedisa. Eltit, Diamela. 2005. "Clases de cuerpo y cuerpos de clase", en revista Aisthesis 38, pp. 9-20.

Rivas, Francisco. 1992. El Banquete. Santiago: Editorial Pehuén. 2001 Martes tristes. Santiago: Al Margen Editores. 